\title{
Existing Building Challenge and CONCERTO Project
}

\author{
Andrea Immendöerfer, Volker Stelzer, Klaus-Rainer Bräutigam and Juliane Jöerissen \\ Institute for Technology Assessment and Systems Analysis, Karlsruhe Institute of Technology, Karlsruhe 76021, Germany
}

\begin{abstract}
If Europe is to achieve the planned transition to a low carbon economy by 2050, succeeding in improving the energy efficiency of the largely inefficient existing building stock will be pivotal. Certain energy efficiency retrofitting obligations have now emerged as part of the EU's Energy Performance in Buildings Directive and the Energy Efficiency Directive. Challenges for retrofitting currently include gaps in technical skills both amongst building trades and professionals, a lack of awareness of building owners and users, concerns about compromising cultural heritage as well as a lack of viable business models, comparatively high cost and resulting long pay-back periods currently hamper the progress. Lessons can be drawn here form the EU-funded initiative CONCERTO, which helped 58 communities in 23 countries to reduce their dependence on conventional energy supply by implementing energy efficiency measures and integrating renewable energy sources not at single building scale but community scale. Almost all of these entailed retrofitting activities had to find solutions to the issues mentioned. This paper presents a selection of conclusions regarding retrofitting to be drawn from the analysis undertaken under the project CONCERTO premium, which analysed outcomes across the 58 projects on behalf of the European Commission and focuses in particular on the political relevance of outcomes.
\end{abstract}

Key words: Existing building stock, retrofitting, refurbishment, renovation, finance, social acceptance, replication.

\section{Introduction}

Despite some retrofitting obligations now emerging as part of the European EPBD (Energy Performance in Buildings Directive) [1] and the Energy Efficiency Directive [2], there is no clear pathway for dealing with the complexities of retrofitting the EU's largely inefficient existing building stock. If Europe is to achieve the targets that it has set itself for 2020 [3] and, furthermore, the planned transition to a low carbon economy by 2050 [4], succeeding in this challenge will be non-negotiable. The EU-funded initiative CONCERTO, a European Commission initiative, which has co-funded 58 communities in 23 countries, demonstrates a considerable number of examples of innovative energy-efficiency and renewable energy technologies for new and, in particular, also existing buildings implemented at community scale. These provide ample learning grounds for the issues faced by retrofitting projects.

Corresponding author: Andrea Immendoerfer, M.Sc., research fields: sustainable energy solutions, climate change mitigation, sustainable construction, sustainable urban development and energy management. E-mail: andrea.immendoerfer@kit.edu.

\section{Concerto}

CONCERTO is being funded by the European Commission under the 6th and 7th framework research programmes (FP6 and FP7). All 58 communities shown on the map of Fig. 1 have received funding. They have been grouped into 22 projects and are spread across 23 countries. All of these proactively address the challenges of creating a more sustainable future for Europe's energy use. Each is working to deliver the highest possible level of energy self-sufficiency. After the initial call for proposals in 2003, the first generation of projects commenced in 2005, two further calls followed. At the time of writing, approximately half of the communities have concluded their project activities. Others are close to finishing. The total amount of the EU co-funding is $€ 175$ million. It typically covered single percentage figures of the overall funding required for each project.

CONCERTO projects do not just address the energy consumption of individual buildings, but the whole neighbourhoods. Every single project is highly complex in itself, as each tackles energy demand by implementing efficiency measures and the supply side 


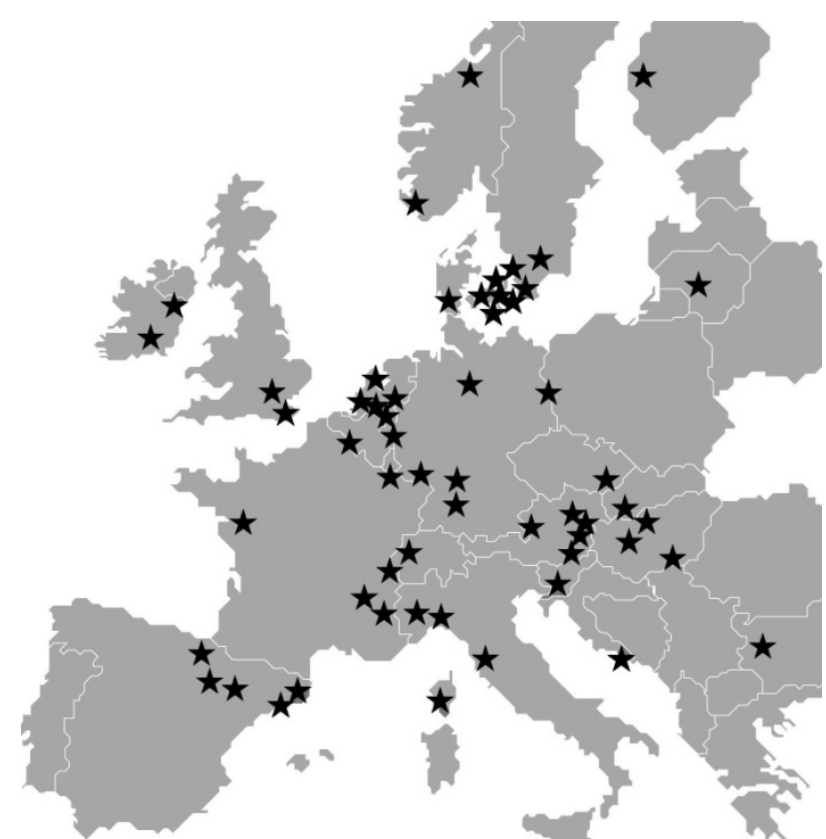

Fig. 1 Map of the 58 CONCERTO projects (project locations shown as stars) [5].

by implementing renewable energy systems, dealing with new buildings as well as refurbished existing buildings and energy supply systems. The projects are similar in their approach and had to respond to very different geographic contexts, which are also reflected in the eventual outcomes: there are dense inner city areas, urban extensions, rural regions and eco-villages. Each site developed tailor-made solutions that fit the local challenges and available renewable energy potentials. As such, each site, therefore, acts as a "real-life-laboratory" and each site is obliged to monitor energy consumption as part of CONCERTO, providing real-life data.

Within the project CONCERTO premium, the authors were involved in the technical, economic and strategic analyses of all CONCERTO projects on behalf of the European Commission. Apart from gathering energy performance data, this also involved paper surveys, interviews and workshops for the coordinators of the 58 sites in order to gain an understanding of political context and soft factors on which this paper is predominantly based. Results are available to the public via a web-based tool at www.concerto.eu.

\section{Defining the Challenge}

It is well known that buildings currently represent almost $40 \%$ of total final energy consumption in the EU [6] and, therefore, the reduction of energy consumption of buildings can make a crucial contribution to the EU targets set for 2020. However, approximately $70 \%$ of the building stock, which we will be using in 2050, is already built.

In total, there are 24 billion $\mathrm{m}^{2}$ floor area in buildings in the European Union, roughly equating to the area of Belgium [6]. This floor area is mainly concentrated in Germany, France, UK, Italy and Spain. As Fig. 2 shows, these are also countries with a considerable share of pre-1990 housing stock [6].

Three quarters of the EU building stock belong to residential buildings, which can be split into one third

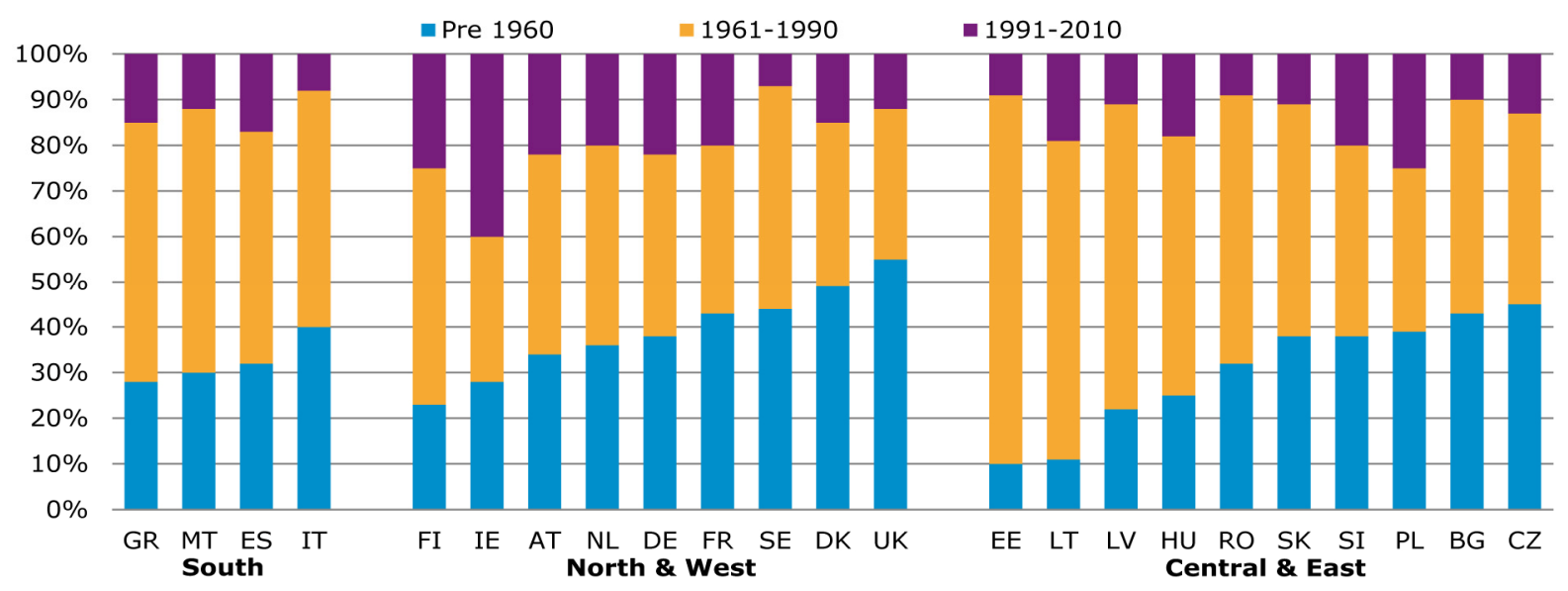

Fig. 2 Age distribution of the housing stock in the EU [6] (redrawn). 
(by floor area) apartment blocks and two thirds single family houses [6], showing the significance of the latter. Another quarter is made up of non-residential buildings.

As figures from the report "Buildings under the Microscope" [6] show by BPIE (Buildings Performance Institute Europe), regardless of whether the building is in Germany, Portugal or Bulgaria, final energy consumption in a single family homes built prior to the $1970 \mathrm{~s}$ is around or above $200 \mathrm{kWh} / \mathrm{m}^{2}$ for heating in different climatic zones and still ranges between $50-100 \mathrm{kWh} / \mathrm{m}^{2}$ for recently built single family homes. For reference, this compares with 15 $\mathrm{kWh} / \mathrm{m}^{2}$ for a new-built passive house and needs to be "near zero" by 2020 in order to fulfil the requirements of the EPBD of 2010. All put together, this illustrates the magnitude of the challenge of inefficient existing buildings and the improvement potential as well.

\section{Retrofitting in CONCERTO}

The wealth of data available from CONCERTO within the publicly accessible database at www.concerto.eu allows for contributions to many energy topics. However, the data on retrofitting projects are considered by the authors to be particularly relevant.

As the financial crisis unfolded, demand for new buildings came to a halt in many countries. Projects often had to shift emphasise onto existing buildings, which now offer the advantage of providing additional learning in this important field. Due to CONCERTO, there are now retrofitting demonstration projects in 23 countries having to respond to a wide range of climatic zones and social contexts as illustrated in Table 1. Hence, varied and comprehensive experience is available both from the analysis of the projects and from input provided by their experienced site coordinators-some technical results are shown in Section 4.1. Based on this, the recommendations in the Sections 4.2-4.5 have been compiled.

\subsection{Energy Savings Achieved}

Based on data provided by the projects, Fig. 3 summarises CONCERTO retrofitting results. Figures provided by the projects were either metered data or based on calculations such as those for energy performance certificates for building regulations approval. It shows that around half of the buildings monitored saved $50 \%$ or more, sometimes saving over $80 \%$ (reasons for lesser favourable performance in Fig. 3 were sometimes found to be the rebound effect or a lack of skills on site, which were identified during interviews with project staff).

Fig. 4 shows calculated final energy demand for heating and domestic hot water in a selection of high-performing refurbished buildings, compared against their previous performance and compared against benchmarks for average national consumption. Substantial savings are evident.

Table 1 Examples of the wide variety of different retrofitting projects within CONCERTO.

\begin{tabular}{|c|c|c|}
\hline Site & $\mathrm{m}^{2}$ retro-fitted & Details \\
\hline $\begin{array}{l}\text { County of North } \\
\text { Tipperary, Ireland }\end{array}$ & $66,300 \mathrm{~m}^{2}$ & $\begin{array}{l}\text { Basic measures to a large number of dwellings across the county as well as an } \\
\text { agricultural college }\end{array}$ \\
\hline $\begin{array}{l}\text { El Picarral, Zaragoza, } \\
\text { Spain }\end{array}$ & $7,700 \mathrm{~m}^{2}$ & $\begin{array}{l}\text { Comprehensive modernization of } 70 \text { dwellings in El Picarral, a working class } \\
\text { neighbourhood }\end{array}$ \\
\hline $\begin{array}{l}\text { Grand Boulevard, } \\
\text { Grenoble, France }\end{array}$ & $400 \mathrm{~m}^{2}$ & Refurbishment of dwellings and commercial space in dense inner city area \\
\hline Hannover, Germany & $40,100 \mathrm{~m}^{2}$ & $\begin{array}{l}\text { Refurbishment of } 35 \text { multi-occupancy buildings with } 350 \text { dwellings plus some } \\
\text { detached houses }\end{array}$ \\
\hline Lambeth, London & $43,000 \mathrm{~m}^{2}$ & Refurbishment of inner city tower blocks serving as social housing \\
\hline Lourdes, Tudela, Spain & $4,800 \mathrm{~m}^{2}$ & $\begin{array}{l}\text { Retrofitting a number of low-rise blocks as a measure to halt the threat of } \\
\text { ghettoization in a culturally mixed area }\end{array}$ \\
\hline Slubice, Poland & $12,800 \mathrm{~m}^{2}$ & Private owner occupiers in mixed tenure refurbishing their block \\
\hline
\end{tabular}




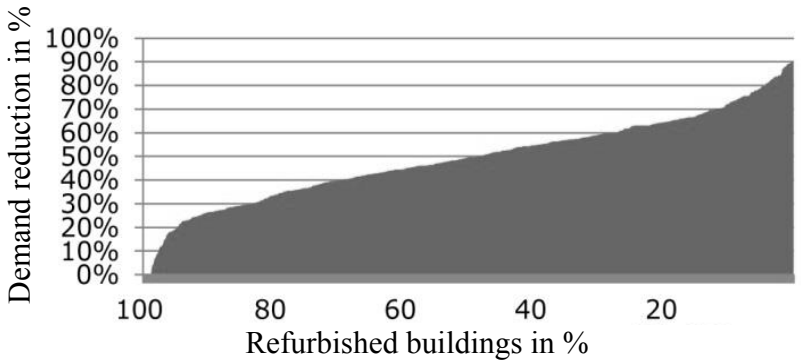

Fig. 3 Final energy demand reduction (\%) of refurbished CONCERTO buildings (heating and hot water) [5].

Nevertheless, these results cannot yet be described as "nearly zero", as required by the EPBD. Some of them, however, use biomass as main heating fuel. This results in the primary energy demand (the metric prescribed for energy performance assessments in the EU by the EPBD) coming close to zero, as shown in Fig. 5. Altogether, the data presented suggest feasible pathway for attaining the longer term ambition of the EPBD to achieve "nearly zero energy", not just in new but also existing buildings. Nevertheless, the analysis of CONCERTO also revealed the difficulties the projects had to overcome. These as well as possible solutions will be discussed in the following sections.

\subsection{Legal Framework, Standards and Quality Control}

Having demonstrated the achievable savings, the following paragraphs consider issues that will be faced if aiming for a wide spread roll-out off retrofitting.
Throughout Europe, energy performance is now part of building regulation, but it focuses mainly on new buildings (though annual growth rate is only about $1 \%$ [6]). Furthermore, compliance of the actual building with planning documents is a huge problem in the construction sector throughout Europe and affects energy performance in particular. Building control inspectors at municipal level are common throughout Europe, but notoriously understaffed and sometimes under-skilled. New strategies of quality assurance must be found in order to reach the energy savings potential in retrofitting. The City of Hannover tried to tackle the issue by developing short courses on quality for designers and architects [7]. The specialist knowledge and skills required of craftsmen and other building professionals for surveys and actual retrofitting works are often lacking, too. Several CONCERTO sites have, therefore, used their projects for training up a retrofitting workforce (e.g., Grenoble, North Tipperary).

In order to set priorities for retrofitting campaigns, appropriate energy survey techniques need to be employed. For example, thermographic imaging has been widely and effectively used within CONCERTO. Simple and low cost measures such as insulating roofs and improving heating controls can achieve high energy savings, especially in eastern European precast concrete block buildings. Some argue that it would be

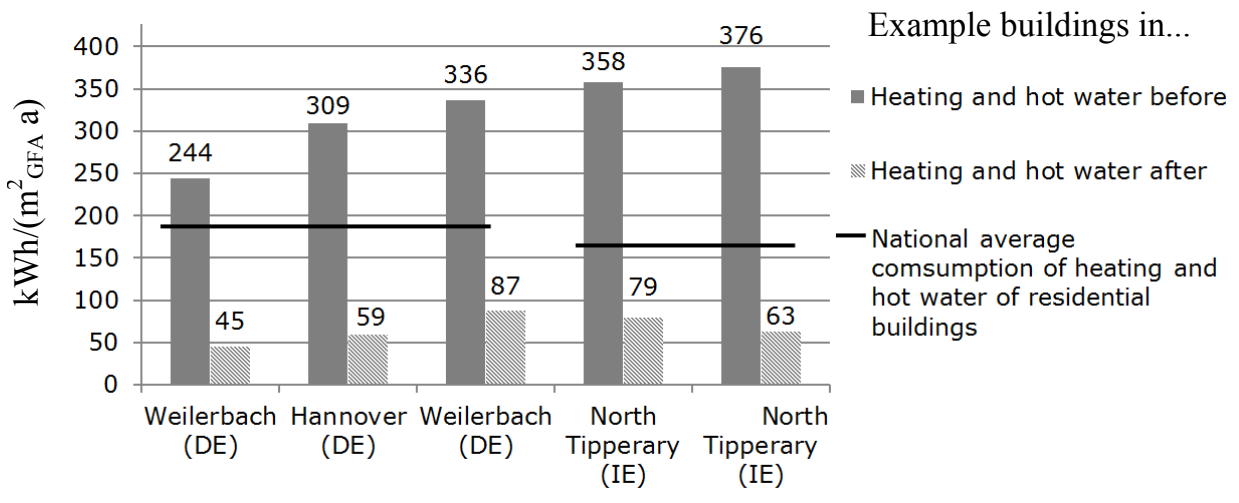

Fig. 4 Examples of final energy demand (calculated) of refurbished residential buildings.

Source: ENTRANZE (Policies to Enforce the Transition to Nearly Zero Energy Buildings in the EU27). 


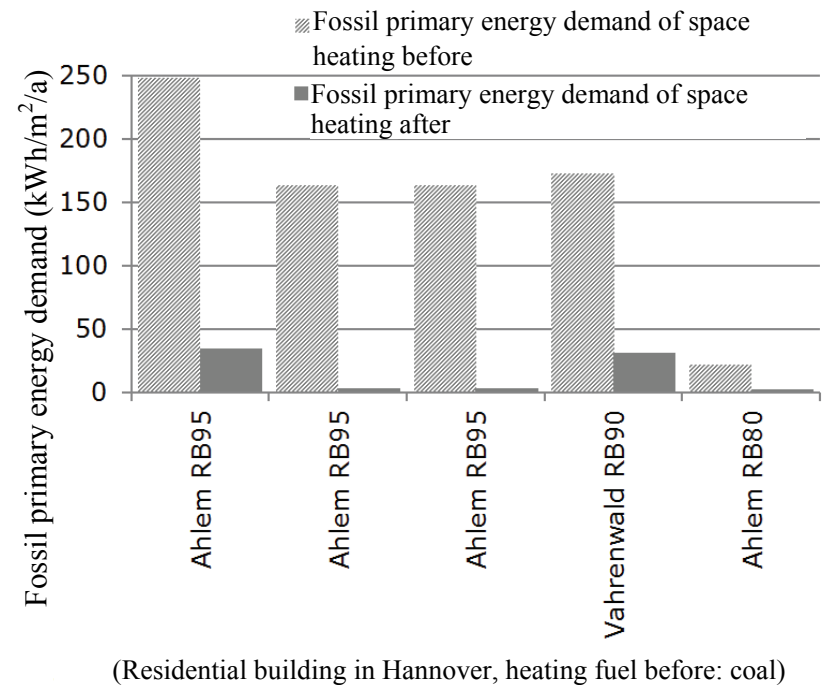

Fig. 5 Fuel switching to biomass: examples of primary energy demand of space heating before and after (Hannover, Germany) [5].

better to implement such inexpensive retrofit measures to a large number of houses instead of refurbishing a small number of houses to net zero energy standards. Both approaches have their merits and both can be found in CONCERTO.

\subsection{Funding and Financing}

The availability of funding for energy saving measures in existing buildings plays a pivotal role, as retrofitting measures will often only pay back after 10-20 years and thus are often seen as not economically viable. Subsidies can not only speed up the refurbishment process but also reduce the costs in the longer term. They do so by kick-starting the processes which allow the required technologies, materials and workflows to reach market maturity and becoming readily available. Certainty for investors is paramount - funding schemes should be available and certain for a long time in order to allow long-term planning. Considering current budgetary constraints in many member states, new sources of funding need to be found, which do not rely on tax revenues. These could be: taxation on fossil fuels, obligations on energy suppliers to fund energy efficiency measures by either providing grants or energy reduction obligations (e.g., regulated using white certificates, as in Denmark, France, Italy and UK). It is furthermore crucial that barriers to energy contracting and ESCOs (energy services companies) are to be removed, e.g., by introducing assurances schemes against bankruptcy of either party. A particular variation of contracting is the "pay-as-you-save" facility "Green Deal" launched in the UK in 2013. Up front capital cost of energy efficiency measures is covered by a utility and repaid by the customer via the utility bill, with payments matching the expected savings [8]. The scheme differs substantially from cheap loan schemes in other EU countries, where uptake depends on creditworthiness of the home owner. The green deal principles may hold potential to address fuel poor households, which often have difficulties applying for credit [9]. So far, it is hoped that other EU member states can learn from the Green Deal.

In several projects, retrofitting of rental properties was hampered by the "principal-agent-problem". Investments have to be made by the building owner, but lower energy bills benefit the tenant. Incentives for landlords need to be strengthened either by regulating allowable rent increases or by including heating costs into the rental charge directly.

\subsection{Acceptance amongst Residents}

Private households contribute over $60 \%$ to total final energy consumption in buildings in the EU [6] and, therefore, have the highest potential for energy savings. The interest of owners of single-family houses in comprehensive retrofits of their homes is low due to high upfront costs and low subsidies. Increasing public awareness for energy issues is therefore important. Information brochures, workshops, lectures, energy days and guided tours to demonstration sites can all play an important role. However, direct one-to-one contact with energy advisors or with early movers in the community has proven particularly powerful. In this context, the offer of vouchers for a visit by an energy advisor, informing about costs, benefits, 
funding options, etc., has proven to be effective in the case of the CONCERTO-project in Hannover, increasing the willingness to refurbish there. Proactive drop-in energy advice centres fulfil the same function and were common in many projects.

If residents remain in a property to be retrofitted, they will be worried about noise, dirt, dust and general disruptions and discomforts arising from the works. Such worries can be alleviated by providing active tenant care throughout, as well as careful coordination of various trades on site. Residents will also need to be informed early on regarding possible changes in rent and energy costs. Advice should also be given after completion of the refurbishment for a certain period to avoid misuse of the new technologies by the inhabitants.

\subsection{Replication Potential}

Despite the many barriers encountered, projects did succeed, albeit with changes to original plans and left legacies that spread beyond the boundaries of the original site. Two substantial reasons for realising the energy efficiency measures are, beside reduction of $\mathrm{CO}_{2}$ and money, the improvement of comfort and look of the buildings (Fig. 6).

During the course of the CONCERTO project in
Lyon, another nearby retrofitting project happened at the same time, collaborated closely in order to learn from the demonstration site.

In Galanta, three multi-storey buildings have initially been retrofitted using CONCERTO finance, three other multi-storey buildings were retrofitted by using bank loans. The fact, which they could see that it is possible to realize such a project, has convinced residents, who now want to retrofit their own blocks of flats.

In Słubice (PL), there are a number of activities that are still ongoing, which grew out of a CONCERTO project: the municipality has applied for funding to refurbish three further schools for which energy audit had been done under CONCERTO.

In Redange, the best practice example of a public building as well as the now readily available information on energy and technical and financial aspects are expected to lead to the refurbishment of a further 350 buildings in the years following their CONCERTO participation.

In Tudela in the district Pamplona, an area will be regenerated based on the CONCERTO approach. The project is called "effi-district" and contains 1,500 dwellings with an old district heating network. The plan is to demonstrate that an effective refurbishment

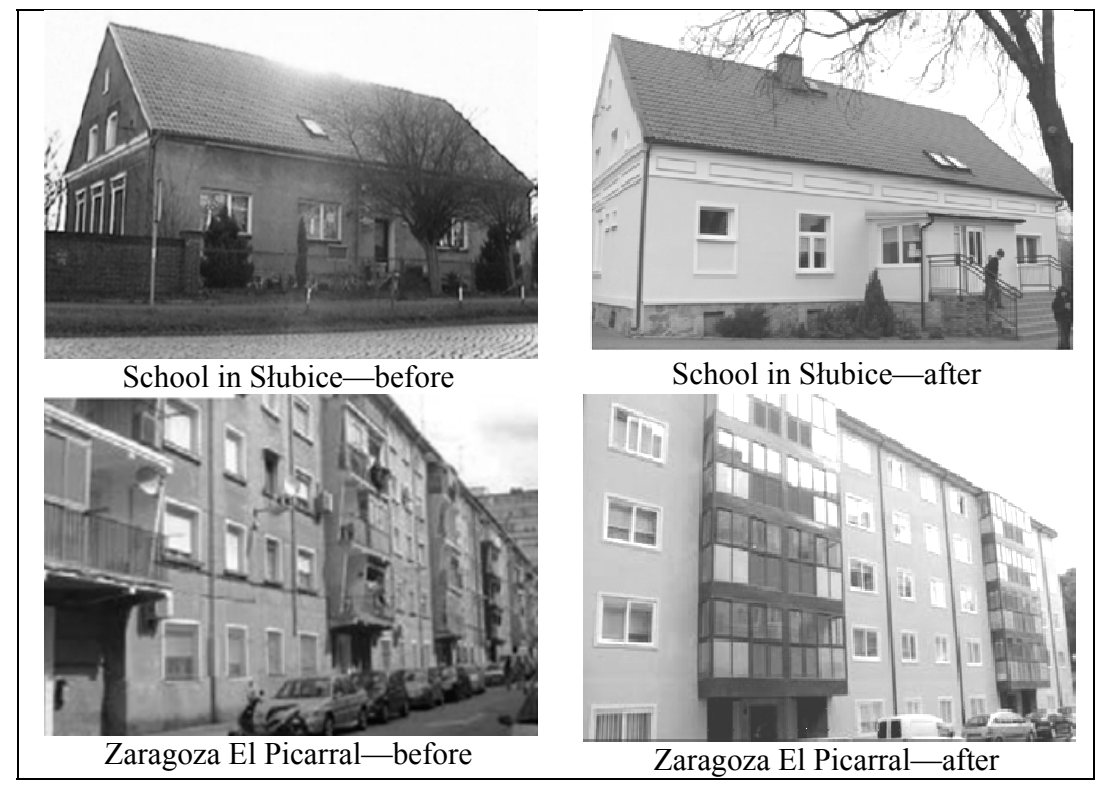

Fig. 6 Houses in Slubice and Zaragoza-before and after refurbishment [5]. 
of district heating systems is possible instead of the usual approach of abandoning district heating in favour of individual systems in each unit.

\section{Conclusions}

The most important message of CONCERTO is simple: it provides proof that retrofitting projects reducing energy consumption at a large urban scale, responding to a wide range of settings which can be done. Substantial savings can be achieved in a wide variety of circumstances and geographic and climatic setting. Furthermore, the data presented suggest a feasible pathway for attaining the longer term ambition of the EPBD to achieve "nearly zero energy", not just in new but also existing buildings. Very low primary energy consumption was achieved, in particular, where biomass was used. However, the projects had to overcome the typically economic, social and structural barriers, especially those of lack of skills and awareness.

Retrofitting activities at community scale within CONCERTO projects play an important role in creating a critical mass of demonstration projects. They provide an evidence base, covering both the barriers encountered but also successfully implemented technical and organisational solutions, which fed the observations and recommendations presented in this paper. There is proof that such projects can inspire successor projects.

Further findings from the analysis of the 58 pilot projects have been published in the report "Energy Solutions for Smart Cities and Communities-Recommendations for Policy Makers" [5]. Further technical data can be accessed here: http://concerto.eu/concerto/db-access.html.

\section{Acknowledgments}

The authors wish to express their gratitude to the many site coordinators of CONCERTO projects, who shared their experiences during workshops and interviews. We would also like to thank our colleagues at the Karlsruhe Institute of Technology, who gathered and analysed the performance data.

\section{References}

[1] Directive 2010/31/EU of the European Parliament and of the Council of 19 May 2010 on the Energy Performance of Buildings, European Parliament, 2010.

[2] Directive 2012/27/EU of the European Parliament and of the Council of 25 October 2012 on Energy Efficiency, European Parliament, 2012.

[3] Communication of 10 January 2007, COM (2007) 1 final-Communication from the Commission to the European Council and the European Parliament an Energy Policy for Europe, Commission of the European Communities, Brussels, 2007.

[4] European Council: 29/30 October 2009 Presidency Conclusions, 15265/1/09 REV 1, Council of the European Union, Brussels, 2009.

[5] A. Immendoerfer, M. Winkelmann, V. Stelzer, Energy Solutions for Smart Cities and Communities-Recommendations for Policy Makers, European Commission, Luxembourg: Publications Office, European Union, 2014.

[6] M. Economidou, Europe's buildings under the microscope, BPIE (Buildings Performance Institute Europe), 2011.

[7] H. Sievers (Ed.), Short Trainings on Quality Assurance, Target GmbH, Hannover, n.d..

[8] Green Deal Initiative [Online], http://www.greendeal initiative.co.uk (accessed Oct. 2013).

[9] P. Guertler, Can the Green Deal be fair too? Exploring new possibilities for alleviating fuel poverty, Energy Policy 49 (2012) 91-97. 